\title{
Thermo-responsive and Self-healing Hydrogel Based on Chitosan Derivatives and Polyoxometalate as an Antibacterial Coating
}

Baoer Fan a,b, Naifu Cui a,b, Zhewei Xu a,b, Kun Chen a,b, Panchao Yin a,b, Kan Yue a,b, Wen Tang ${ }^{\mathrm{a}, \mathrm{b}} *$

\begin{abstract}
Affiliations:
${ }^{a}$ South China Advanced Institute for Soft Matter Science and Technology, School of Molecular Science and Engineering, South China University of Technology, Guangzhou 510640, China.

${ }^{\mathrm{b}}$ Guangdong Provincial Key Laboratory of Functional and Intelligent Hybrid Materials and Devices, South China University of Technology, Guangzhou 510640, China.
\end{abstract}

\section{Corresponding author}

Wen Tang (Email address: tangw@scut.edu.cn)

\section{List of Tables and Figures}

Table S1 Feeding ratio and yield corresponding to $N$-acetylated glycol chitosan ....................2

Figure S1. ${ }^{1} \mathrm{H}$ NMR spectra of glycol chitosan with different degrees of $\mathrm{N}$-acetylation. ..........2

Table S2 Main vibration bands in the FT-IR spectra of $\mathrm{CMC}, \mathrm{AgP}_{5} \mathrm{~W}_{30}$, and hydrogel.............3

Figure S2. ${ }^{31} \mathrm{P}$ NMR spectra of $\mathrm{AgP}_{5} \mathrm{~W}_{30}$ and $\mathrm{AgP}_{5} \mathrm{~W}_{30}$ released from the hydrogel................

Figure $\mathrm{S} 3$. Antibacterial effects of $\mathrm{AgP}_{5} \mathrm{~W}_{30}, \mathrm{CMC}$, and $\mathrm{AgP}_{5} \mathrm{~W}_{30}-\mathrm{CMC}$ hydrogels................ 
Table S1 Feeding ratio and yield corresponding to $N$-acetylated glycol chitosan

\begin{tabular}{ccc}
\hline $\begin{array}{c}\text { Degree of } N- \\
\text { acetylation }(\%)\end{array}$ & $\begin{array}{c}\text { Feeding ratio } \\
\text { Glycol chitosan: } \mathrm{Ac}_{2} \mathrm{O}\end{array}$ & Yield (\%) \\
\hline 91 & $1: 10$ & 90.7 \\
69 & $1: 1$ & 91.0 \\
52 & $1: 0.5$ & 94.0 \\
36 & $1: 0.25$ & 89.7 \\
13 & Glycol chitosan raw material \\
\hline
\end{tabular}

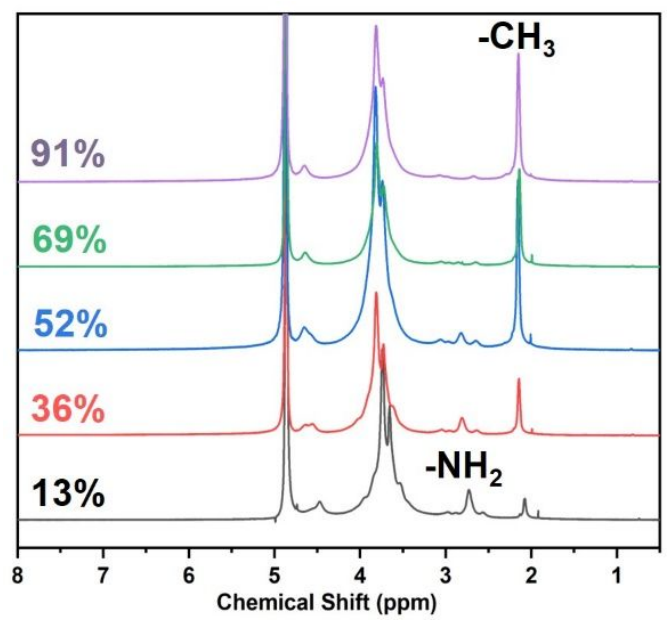

Figure S1. ${ }^{1} \mathrm{H}$ NMR spectra of glycol chitosan with different degrees of $\mathrm{N}$-acetylation. 
Table S2 Main vibration bands $\left(\mathrm{cm}^{-1}\right)$ of FT-IR spectra of $\mathrm{CMC}, \mathrm{AgP}_{5} \mathrm{~W}_{30}$, and hydrogel.

\begin{tabular}{|c|c|c|}
\hline $\mathrm{CMC}$ & $\mathrm{AgP}_{5} \mathrm{~W}_{30}$ & $\begin{array}{l}\mathrm{AgP}_{5} \mathrm{~W}_{30}-\mathrm{CMC} \\
\text { hydrogel }\end{array}$ \\
\hline$v(\mathrm{H}-\mathrm{O}), v(\mathrm{H}-\mathrm{N}): 3500$ & $v(\mathrm{H}-\mathrm{O}): 3500$ & $v(\mathrm{H}-\mathrm{O}), v(\mathrm{H}-\mathrm{N}): 3500$ \\
\hline \multirow[t]{6}{*}{$v(\mathrm{C}=\mathrm{O}): 1605$} & 1617 & 1617 \\
\hline & $v(\mathrm{Ag}-\mathrm{O}): 1383$ & $v(\mathrm{Ag}-\mathrm{O}): 1383$ \\
\hline & $v(\mathrm{P}-\mathrm{O}): 1158$ & $v(\mathrm{P}-\mathrm{O}): 1158$ \\
\hline & $v(\mathrm{P}-\mathrm{O}): 1079$ & $v(\mathrm{P}-\mathrm{O}): 1079$ \\
\hline & $v_{\mathrm{as}}(\mathrm{W}-\mathrm{O}): 935$ & $v_{\mathrm{as}}(\mathrm{W}-\mathrm{O}): 935$ \\
\hline & $v_{\mathrm{as}}(\mathrm{W}-\mathrm{O}-\mathrm{W}): 911$ & $v_{\text {as }}(\mathrm{W}-\mathrm{O}-\mathrm{W}): 911$ \\
\hline
\end{tabular}

As shown in Figure S2, the higher characteristic peak with a chemical shift of -9.8 ppm corresponds to $\mathrm{P}$ atoms in the center of $\mathrm{AgP}_{5} \mathrm{~W}_{30}$, and the lower characteristic peak with a chemical shift of -9.5 ppm corresponds to $\mathrm{P}$ centers in $\mathrm{NaP}_{5} \mathrm{~W}_{30}$. The characteristic peak of $\mathrm{NaP}_{5} \mathrm{~W}_{30}$ in the NMR spectrum may be due to the small amount of $\mathrm{Na}^{+}$replaced $\mathrm{Ag}^{+}$in the POM cage when $\mathrm{K}_{13} \mathrm{Na}\left[\mathrm{AgP}_{5} \mathrm{~W}_{30} \mathrm{O}_{110}\right]$ was dissolved in $\mathrm{D}_{2} \mathrm{O}$. The structure of $\mathrm{AgP}_{5} \mathrm{~W}_{30}$ is still dominant, so the characteristic peak is also higher. After $\mathrm{AgP}_{5} \mathrm{~W}_{30}$ is released from hydrogel in water, the position and intensity of the characteristic peak are basically the same as before the release, which proves that the structure of the POM remains intact and the $\mathrm{Ag}^{+}$is still in the cage. 


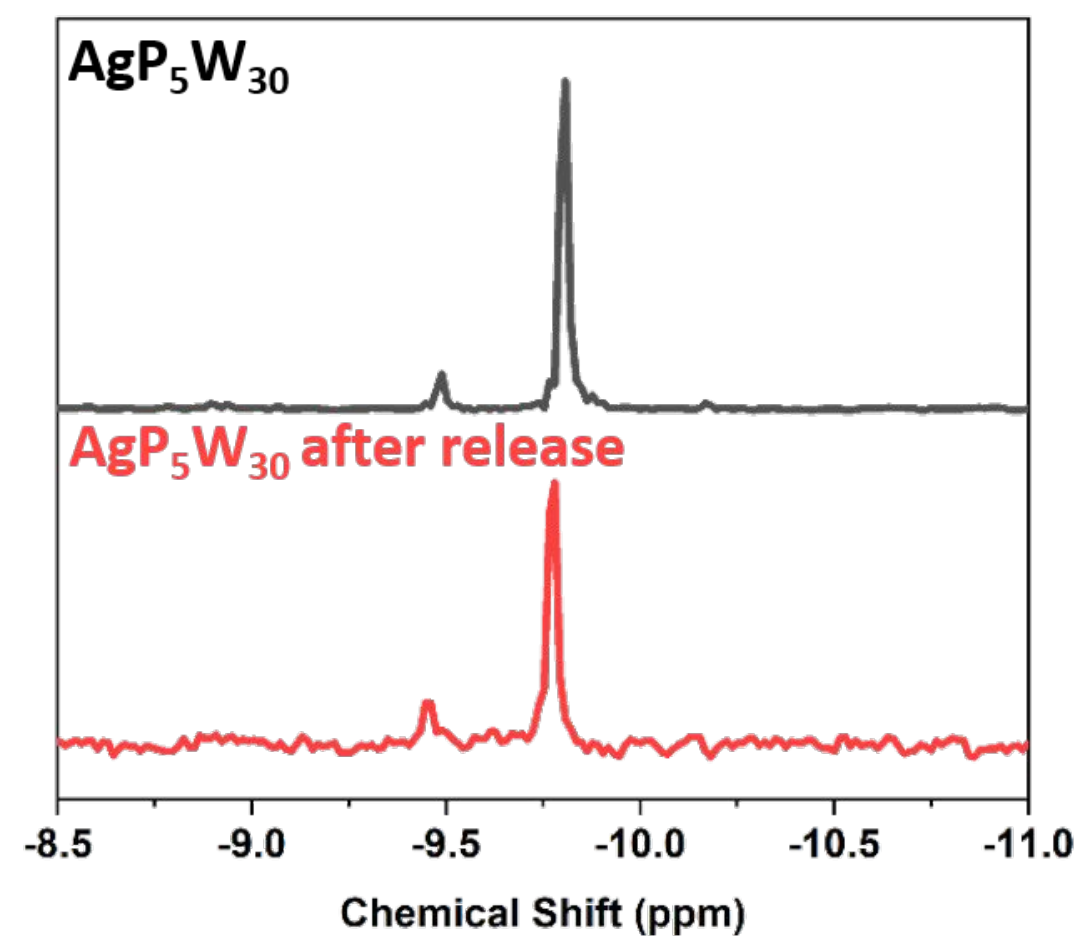

Figure S2. ${ }^{31} \mathrm{P}$ NMR spectra of $\mathrm{AgP}_{5} \mathrm{~W}_{30}$ and $\mathrm{AgP}_{5} \mathrm{~W}_{30}$ released from the hydrogel.

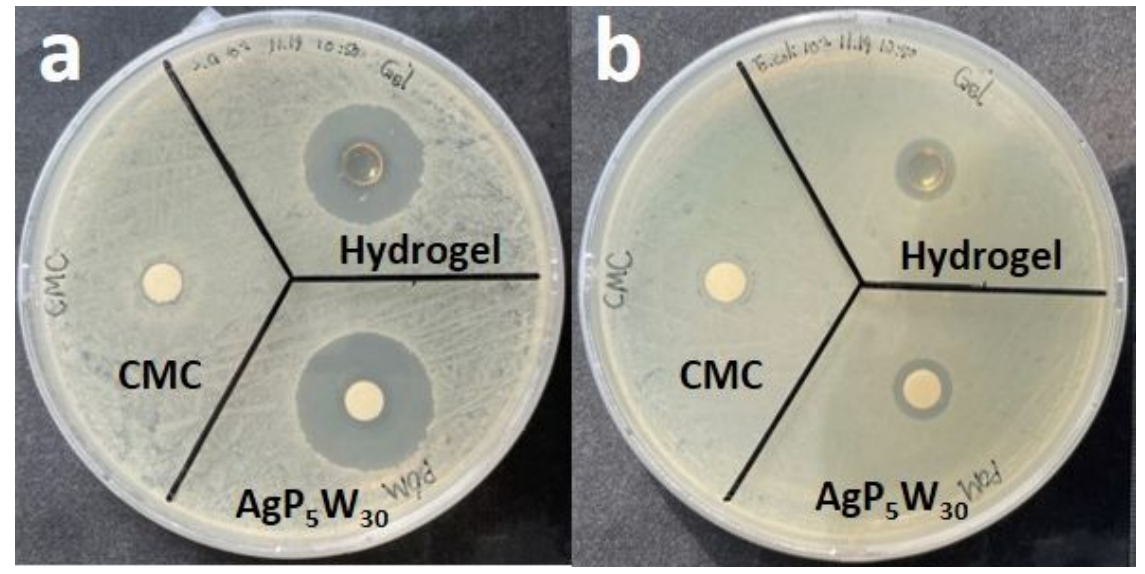

Figure S3. Antibacterial effects of $\mathrm{AgP}_{5} \mathrm{~W}_{30}, \mathrm{CMC}$, and $\mathrm{AgP}_{5} \mathrm{~W}_{30}-\mathrm{CMC}$ hydrogels. (a) Antibacterial effect on $S$. aureus. (b) Antibacterial effect on E. coli. 